\title{
Editorial
}

\section{Air-Sea Interactions and Marine Meteorology}

\author{
Lian Xie, ${ }^{1}$ Bin Liu, ${ }^{1}$ John Morrison, ${ }^{2}$ Huiwang Gao, ${ }^{3}$ and Jianhong Wang ${ }^{4}$ \\ ${ }^{1}$ North Carolina State University, Raleigh, NC 27695, USA \\ ${ }^{2}$ University of North Carolina Wilmington, Wilmington, NC 28409, USA \\ ${ }^{3}$ Ocean University of China, Qingdao, Shandong 266100, China \\ ${ }^{4}$ Nanjing University of Information Science and Technology, Nanjing, Jiangsu 210044, China
}

Correspondence should be addressed to Lian Xie; xie@ncsu.edu

Received 10 November 2013; Accepted 10 November 2013

Copyright (C) 2013 Lian Xie et al. This is an open access article distributed under the Creative Commons Attribution License, which permits unrestricted use, distribution, and reproduction in any medium, provided the original work is properly cited.

Marine meteorology is a subfield of meteorology which deals with the monitoring, analysis, modeling, and forecasting of the weather and associated oceanographic conditions in marine and coastal environments. The fundamental processes which distinguish marine meteorology from other subfields of meteorology are the interactions between the ocean and the atmosphere. The challenges in advancing the understanding and forecasting of marine weather lie in the complexities of different marine environments from the open ocean to the coastal zone and from tropical islands to highlatitude marginal seas and the broad dynamic scales in air-sea interactions from microscales to local, regional, and global scales.

This special issue publishes a collection of 12 articles covering a wide range of topics of growing importance in our understanding of "air-sea interactions and marine meteorology" from tropical cyclones to polar lows, from the impact of climate change on the marine environment in the vicinity of the Galapagos islands to deep convections over the Barbados island, from the processes that occur within the ocean skin layer to the entire mixed layer, from typhoons affecting East Asia to landfalling hurricanes affecting the US southeast coast, and from weather support for summer Olympics and Paralympics to weather analysis on oil platforms. These articles reflect the recent advances and applications in "air-sea interactions and marine meteorology" from a set of unique angles.

The subject of tropical cyclones has always been a trendy topic in both air-sea interactions and marine meteorology. A total of five articles included in this special issue dealt with tropical cyclones. Ever since the discovery of the decreasing trend of drag coefficient at high wind conditions by Powell and his colleagues in 2003 (Nature 422, Pages 279-283), the subject of drag coefficient in typhoon and hurricane environments has been vigorously studied. In B. Wang et al's paper, the drag coefficients were estimated using data from wind towers during typhoons Hagupit and Nuri. They also examined the relationship between drag coefficient and atmospheric stability and found that the drag coefficient decreased when atmosphere stability changed from weakly stable or unstable to neutral, and although the relationships between drag coefficient and wind speed were similar to other researchers' results, the wind thresholds were different due to different observation sites. In N. Huang et al.s paper, the buoy observation network in the East China Sea is used to assist the determination of the characteristics of the structure of two tropical cyclones in August 2012. The buoymeasured wind and pressure time series were also used to correct the intensity of one of the typhoons "Damrey" initially determined by China Meteorological Administration. $\mathrm{H}$. Xu et al. also studied two tropical cyclones (Saomai and Bopha) in 2006 but focused on the mutual influence between them using a numerical model. They concluded that the impact of Tropical Storm Bopha on Saomai is regarded as a binary tropical cyclone interaction in which moisture transport is a pivotal process. The interaction between Typhoon Choiwan (2009) and the Kuroshio Extension was examined in the paper by A. Wada et al. using a coupled atmosphere-waveocean model. They showed that variations in preexisting oceanic conditions in the Kuroshio Extension region on the 
simulated atmospheric and oceanic horizontal fields affected the simulated central pressure and the inner-core axisymmetric structure of the simulated typhoon differently during the intensification, mature, and decaying phases, but they had little impact on the simulated track. In Q. Tang et al.s paper, the impact of landfalling tropical cyclones on inland precipitation and river stream flow was simulated by a multinesting numerical model and a hydrological river stream flow model. Their study demonstrated the potential application of using a linked numerical weather prediction model and a hydrological model to advance the simulation of inland precipitation and flooding due to landfalling tropical cyclones. Their study further demonstrated that only $10 \%$ of the total discharge at the Tarboro, NC, gauge station, was the result of the background synoptic pattern, with the remaining $90 \%$ of the record amount of flood water in the Tar Pamlico river basin due to interactions between two tropical systems, Hurricane Floyd and Hurricane Dennis.

Simultaneous in situ measurements of air-sea fluxes together with parameters on both sides of the air-sea interface under various marine atmospheric boundary environments are critical to understanding air-sea interaction processes and improving the parameterizations of air-sea fluxes. In $\mathrm{B}$. Wu et al.s paper, the authors presented the results based on the in situ measurements of atmospheric and oceanic variables from an oil platform in the Bohai Gulf during early mid-August in 2011. They analyzed the basic meteorological and hydrological characteristics of the Bohai Gulf, as well as the characteristics of momentum, sensible, and latent heat fluxes during the observational period. As a ubiquitous phenomenon at airsea interface, the existence of sea surface waves modifies the boundary layer in both sides of the air and water interface, which in turn impacts atmosphere-wave, wave-ocean, and atmosphere-ocean interactions. One of the wave-current interaction processes is due to the wave-induced CoriolisStokes Forcing (CSF). Z. Deng et al.s paper investigated the impacts of the wave-induced CSF on ocean mixed layer dynamics by introducing a new CSF term based on the wave parameters simulated by the WaveWatch III (WW3) model in the Hybrid Coordinate Ocean Model (HYCOM). Their results show that CSF can cause noticeable influence on ocean circulation in the mixed layer. They also analyzed the seasonal variability caused by CSF in the mixed layer temperature and depth. R. Nehorai et al. focused on the temperature in the "skin" or the upper few millimeters of the ocean. They analyzed the dynamics of the skin temperature of the Dead Sea using continuous measurements of the skin and bulk water temperatures and short wave and long wave radiation, with wind speed and air temperature from a buoy located near the center of the lake. They found that the skin, with its low thermal inertia, responds immediately to the governing forcing. Thus, the air temperature with its highest correlation and minimal time lag is considered to be the most important factor in forcing the skin layer's temperature, which is accomplished primarily through the sensible heat flux.

Two papers discussed the downscaling from large-scale climatic circulation to regional scales. In the paper by F. Chen and H. von Storch, the 6-hourly 1948-2010 NCEP reanalyses have been dynamically downscaled for the region of the
North Pacific. With a detecting-and-tracking algorithm, the climatology of North Pacific polar lows has been constructed. This derived climatology is consistent with the limited observational evidence in terms of frequency and spatial distribution. The climatology exhibits strong year-to-year variability but weak decadal variability and a small positive trend. A canonical correlation analysis describes the conditioning of the formation of polar lows by characteristic seasonal mean flow regimes, which favor, or limit, cold air outbreaks and upper air troughs. In the paper by Y. Liu et al., the regional impact of global climate change on the ocean circulation around the Galápagos Archipelago was studied by using the Hybrid Coordinate Ocean Model (HYCOM). The potential impact of future anthropogenic global warming in the Galápagos region was examined using the HYCOM driven by atmospheric forcings from the projections of Intergovernmental Panel on Climate Change, Fourth Assessment Report (IPCC-AR4). It was shown that the oceanic variability in the entire Galápagos region is substantially affected by global climate change, while with the degree of such effects being inhomogeneous across the region. The inhomogeneous responses in different regions of the Galápagos Archipelago to future anthropogenic global warming can be explained by the incoherent changes of the various current systems in the Galápagos region as a result of global climate change.

Another paper dealing with marine weather in island environment was by K. Whitehall et al. This paper discussed the localized convections in Barbados islands and found that such convections accounted for hazardous conditions and a significant percentage of the island's annual rainfall. Weather Research and Forecasting model (WRF) simulations are conducted for a rapid convective initiated and heavy precipitation event of 26 August 2008 over Barbados. The simulation results from the $1 \mathrm{~km}$ grid resolution domain depict that the shallow topography on the island plays a significant role in enhancing convective activity under weak synoptically disturbed conditions. The model results also demonstrate that the driving forces for the development of deep convective clouds include low-level moisture convergence that forms as a result of the temperature differential between the land and the ocean and forced low-level uplift as a result of the blocking by the topography. The high-resolution WRF simulations demonstrate their capability to accurately capture the lowlevel flow over the island, as well as the orientation of the divergence and convergence patterns throughout the depth of the atmosphere. These results are heartening to use the WRF as a resource for studying deep convection in Barbados for disaster managers and water resource managers.

The final paper by Y. Ma et al. presented the application of a marine weather support system during the 2008 Beijing Olympic and Paralympic sailing competition. The weather support system includes monitoring, forecasting, and networking systems which have been constructed, evaluated and improved through weather support for the 2006 and 2007 international regattas and the 2008 international regatta for the handicapped. This is a multimodel high-resolution sea surface wind forecast system supported by the comprehensive observation system including weather radars, wind profile radars, buoys, automated weather stations, and other 
conventional observations. Five dynamical models and two statistical modules were included in the forecast system. The refined forecasting system was able to provide point-specific hourly wind forecasts and the prediction of rainstorms, gales, and hailstones. Moreover, latest forecasting products, warnings, and weather information were communicated conveniently and timely through a synthetic, speedy, and digitalized network system to different customers, such as notification boards, websites, and community short messages. This weather support system provides a model for refined weather forecast services to the public in China.

The twelve papers in this special issue presented a collection of recent research results in "air-sea interactions and marine meteorology." We hope they are of interest to peers.

\section{Acknowledgment}

We would like to thank all of the authors, reviewers, and support staff from the editorial office for making this special issue possible.

Lian Xie

Bin Liu

John Morrison

Huiwang Gao

Jianhong Wang 

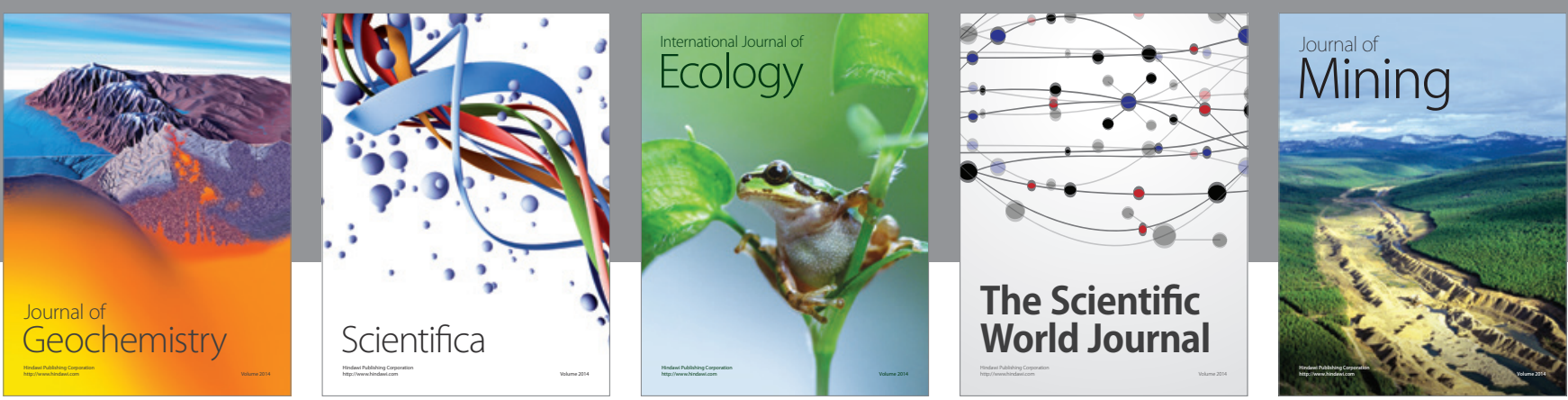

The Scientific World Journal
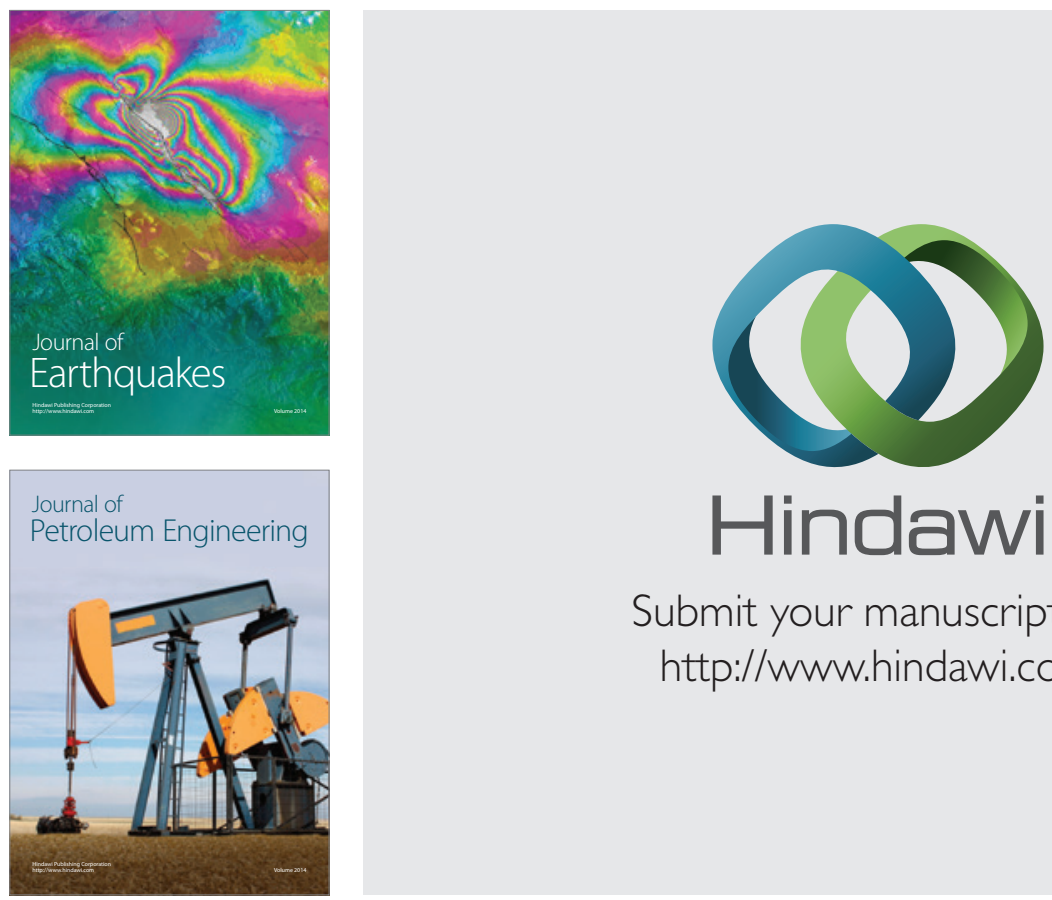

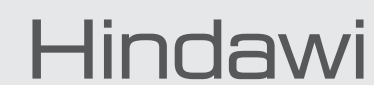

Submit your manuscripts at

http://www.hindawi.com
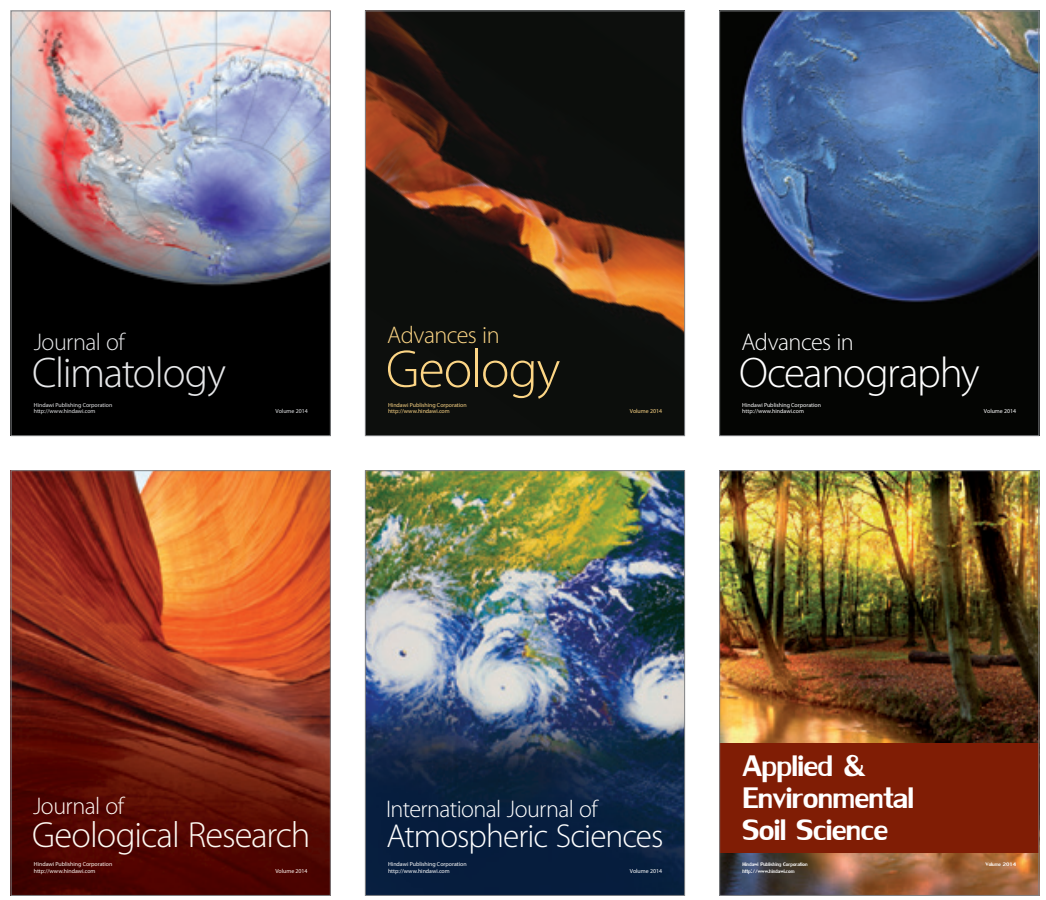
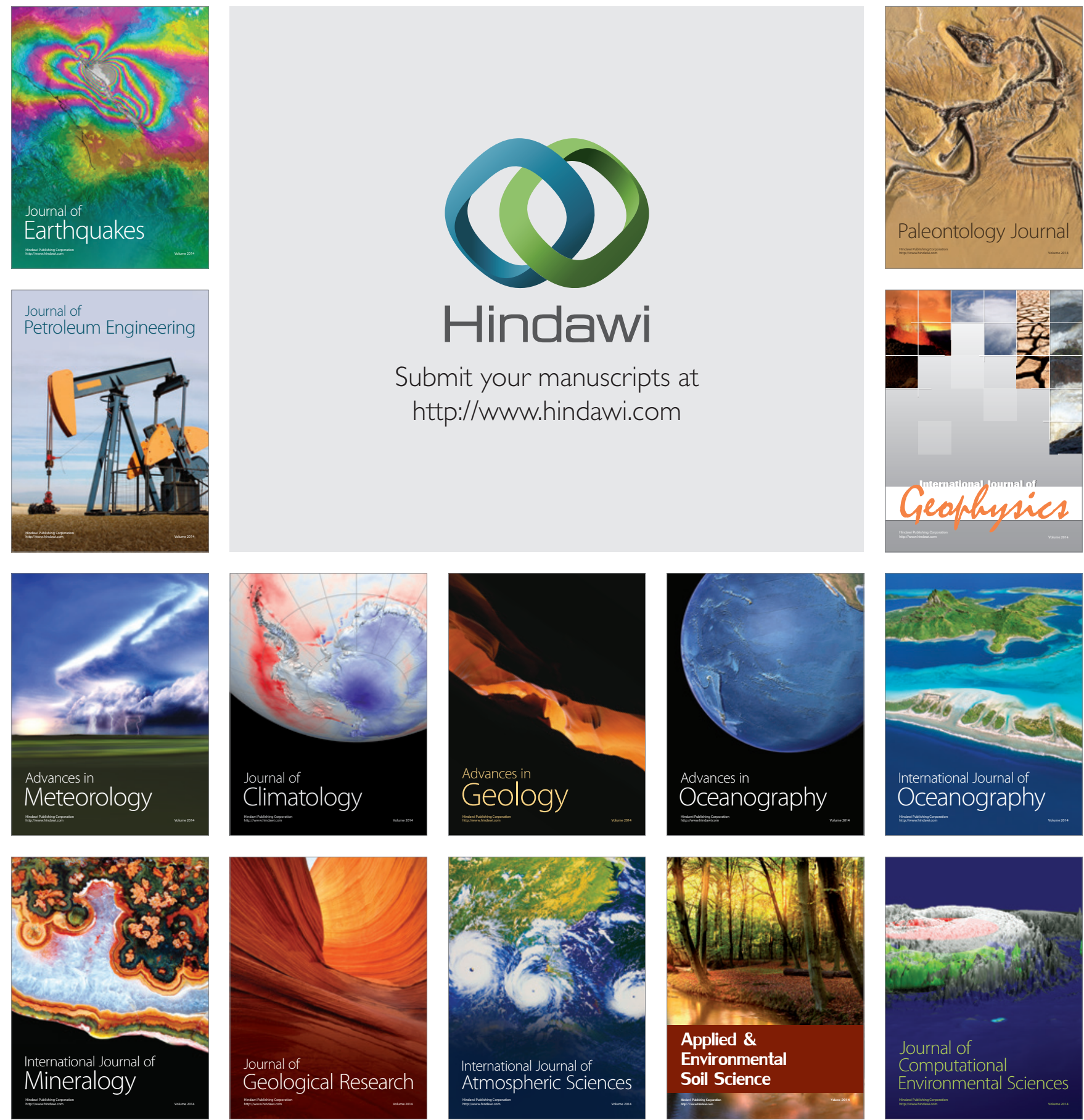